\title{
Nonlinearity And The Forward Premium Anomaly
}

Apostolos Xanthopoulos, Illinois Institute Of Technology

\begin{abstract}
Speculative efficiency (the ability to profit without bearing commensurate risk in foreign exchange markets) is predicated on the forward premium anomaly. Market efficiency still manifests itself in the form of nonlinear adjustments, eroding excess profits. The returns on foreign exchange speculation may not behave in a market-efficient manner except at average values of interest-rate differentials. This study suggests that market efficiency holds as a result of a hedging relation between linear and nonlinear responses of returns.
\end{abstract}

Keywords: Efficient-market hypothesis, speculative returns, hyperbolic-tangent response, hedging.

\section{INTRODUCTION}

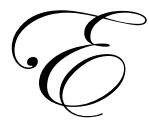

mpirical evidence that contradicts anticipated economic relationships lead researchers to the exploration of nonlinear systems. Returns from foreign exchange speculation are one such relationship examined here. The forward premium anomaly partly explains excess profits from speculation in foreign exchange markets. Corrections abruptly reverse such profits, lending support to the original concept of efficient markets. This analysis captures both effects in a single equation, and ultimately lends support to market efficiency. A nonlinear term is simply added to the common linear asset return estimation. This is an ANN(1) system that points to a relation between linear anomaly and nonlinear efficiency across currencies.

\subsection{The Efficient Market Hypothesis}

The forward premium anomaly refers to the finding that changes in spot exchange rates are inversely related to the premium of forward rates over future spot rates. A large number of studies regress the percentage change in spot against interest rate differentials and, instead of $\beta=1$, find a near-zero or negative coefficient. These studies run regressions of the log-return of the spot rate against the interest rate differential and test the hypothesis that the intercept is zero, the slope is one and errors are serially uncorrelated, in the model:

$s_{t+1}-s_{t}=\alpha+\beta \cdot\left(i-i^{*}\right)+\varepsilon_{t}$

The stipulation is that the expected returns on currency speculation based on available information are zero. Based on Hansen and Hodrick (1980), the simple efficiency model is stated as follows: ${ }^{1}$

Efficient Market Hy pothesis: $f_{t, k}=E\left[s_{t+k} / I_{t}\right]$

$s_{t}=\ln S_{t}$, the logarithm of the spotrate

$f_{t, k}=\ln F_{t, k}$, the logarithm of the forward rate

$s_{t+k}-f_{t, k} \approx$ rate of return tospeculation (should be zero)

$I_{t}$ is the information set available to agents at time $t$.

\footnotetext{
${ }^{1}$ Lars Peter Hansen and Robert J. Hodrick, Forward Exchange Rates as Optimal Predictors of Future Spot Rates: An Econometric Analysis, Journal of Political Economy, Oct. 1980, 829-853.
} 
Fama (1984) finds that forward premia are made of time-varying risk premia and future spot expectations. Both components vary through time, but most of the variation is in risk premia. ${ }^{2}$ The forward premium is the sum of the risk premium and the expected rate of appreciation, but the two are inversely related, as evidenced by the negative coefficient found in the conventional models. Because $\beta_{1}<0$, an increase in the interest differential (dollar minus foreign currency) leads to an expected dollar appreciation. The variance of the risk premium is greater than that of both the expected appreciation and the interest rate differential.

\subsection{Nonlinear Systems}

The above models are linear in their coefficients. Adding a transfer function with a separate coefficient set helps detect nonlinear effects. The most common transfer function is the following sigmoid logistic function, in which $i$ is the index for inputs $x_{i}, w_{i}$ is a weighting factor and $w_{0}$ is the neuron bias: ${ }^{3}$

$$
\text { output }=\frac{1}{1+e^{-\left(\sum w_{i} x_{i}+w_{0}\right)}}
$$

This monotonic, continuous and differentiable function approaches a step function, but allows for varying degrees of smoothness of transition across two states or regimes. Frances and van Dijk (2000) delineate a theoretical path from states of the world or regimes to sigmoid functions. ${ }^{4}$ State-dependent properties of a time series may vary across different regimes, and the regime process may be stochastic. In a simple AR(1) model with parameters that are allowed to depend on the regime or state, it can be assumed that the regime is determined by an observable variable relative to a threshold variable. In a Threshold Autoregressive Model (TAR) this observable variable is a lagged value of the time series itself, and the threshold variable $c$ helps determine the switching of returns from one state to the other:

$$
r_{t}=\left(\varphi_{0,1}+\varphi_{1,1} \cdot r_{t-1}\right)\left(1-\mathrm{I}_{\left[r_{t-1}>c\right]}\right)+\left(\varphi_{0,2}+\varphi_{1,2} \cdot r_{t-1}\right)\left(\mathrm{I}_{\left[r_{t-1}>c\right]}\right)
$$

When the continuous logistic function $G\left(y_{t-1} ; \gamma, c\right)$ replaces indicator function $\mathrm{I}_{[.]}$the transition between states begins to acquire varying degrees of smoothness. The resulting model becomes a Smooth Threshold Autoregressive one (STAR) and $c$ is the threshold around which the function changes from 0 to 1 :

$$
G\left(y_{t-1} ; \gamma, c\right)=\frac{1}{1+\exp \left(-\gamma \cdot\left[y_{t-1}-c\right]\right)} ; \quad G(c ; \gamma, c)=\frac{1}{1+\exp (-\gamma \cdot[0])}=0.5
$$

The representation of the STAR model is:

$$
\begin{aligned}
& r_{t}=\beta_{0}+\beta_{1} \cdot G\left(\gamma \cdot\left[y_{t-1}-c\right]\right)+\varepsilon_{t} ; \text { where } G(z)=\frac{1}{1+\exp (-z)} ; \text { or, } \\
& r_{t}=\beta_{0}+\beta_{1} \cdot \frac{1}{1+\frac{1}{\exp \left(\gamma\left[y_{t-1}-c\right]\right)}}+\varepsilon_{t}
\end{aligned}
$$

The transition function of this analysis is the hyperbolic tangent and is based on interest-rate differentials. This function is more appropriate than the logistic because it ranges from -1 to 1 and has an expected value of zero, similar to expected asset returns. The result is a model in which asset returns $R_{i, t}$ may depend on an otherwise

\footnotetext{
${ }^{2}$ Eugene F. Fama, Forward and Spot Exchange Rates, Journal of Monetary Economics, 1984, 319-338.

${ }^{3}$ Kevin L. Priddy and Paul E. Keller, Artificial Neural Networks: An Introduction (SPIE-The International Society for Optical Engineering, 2005), p. 5.

${ }^{4}$ Philip Hans Franses, and Dick van Dijk, Nonlinear Time Series Models in Empirical Finance (Cambridge University Press, 2000), pp. 69-250.
} 
normally distributed interest-rate differential index $I_{t}$ in a linear, as well as a nonlinear manner. It is assumed that $\varepsilon \sim$ $\left(0, \sigma^{2}\right)$ and $\varsigma \sim\left(0, \omega^{2}\right)$ with variances unspecified. The equation for a single-asset return based on any hypothetical market-index return $R_{M}(t)$ is shown below. This model-equation incorporates a hyperbolic tangent function in the estimation of cross-currency returns as the latter respond to the index of interest rate differentials. Index values of $R_{M}(t)$ can be lagged and contemporaneous. The returns of seven currencies based on their interest-rate differentials with the US dollar are jointly estimated through seemingly unrelated regressions.

$$
\begin{aligned}
& R_{i, t}=\alpha_{i}+\beta_{i} \cdot I_{t}+\phi \cdot \frac{e^{\gamma_{i}+\delta_{i} I_{t}+\zeta_{i, t}}-e^{-\gamma_{i}-\delta_{i} I_{t}-\zeta_{i, t}}}{e^{\gamma_{i}+\delta_{i} I_{t}+\zeta_{i, t}}+e^{-\gamma_{i}-\delta_{i} I_{t}-\zeta_{i, t}}}+\varepsilon_{i, t} \\
& R_{i}(t)=\alpha_{i}+\beta_{i} \cdot R_{M}(t)+\phi_{i} \cdot\left(1-\frac{2}{e^{2\left(\gamma_{i}+\delta_{i} \cdot R_{M}(t)+\zeta_{i}\right)}+1}\right)+\varepsilon_{i}(t) \\
& =\alpha_{i}+\beta_{i} \cdot R_{M}(t)+\phi_{i} \cdot\left(1-\frac{2}{e^{2 \cdot g_{i}\left(R_{M}(t)\right)}+1}\right)+\varepsilon_{i}(t)
\end{aligned}
$$

where $g_{i}\left(R_{M}(t)\right)=\gamma_{i}+\delta_{i} \cdot R_{M}(t)+\zeta_{i}(t)$

In Figure 1 below a hypothetical nonlinear response $\delta=-7.50$ and return sensitivity to nonlinearity $\varnothing=0.01$ in conjunction with a linear term produce leptokurtotic returns while the index is normally distributed.

Figure 1 Leptokurtotic Asset Returns as a Result of Nonlinear Response to Index

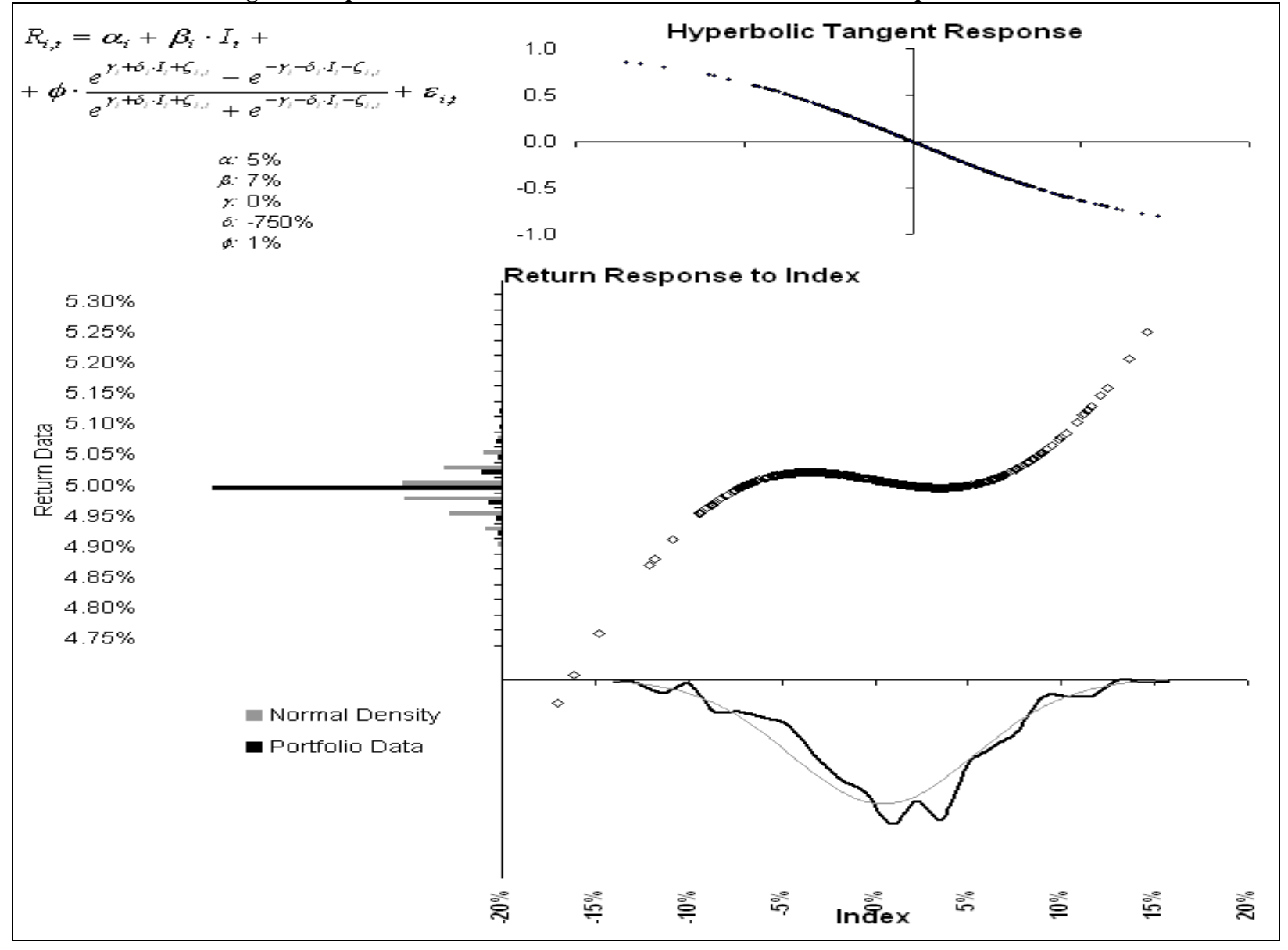




\section{ECONOMETRIC MODEL}

Maximum likelihood estimation is performed on ten years of monthly interest rates and spot exchange rates between 9/1995 and 6/2006 for the Australian dollar, Canadian dollar, Euro, Japanese yen, Swiss franc, British pound and the New Zealand Dollar in reference to the US dollar. The linear term of the model captures the forward premium anomaly while the nonlinear term accommodates the transition between states commonly associated with market efficiency. Conclusions about efficiency are drawn from the fact that these effects are linked in a hedging relation at the average values of interest-rate differentials.

\subsection{Expectations And Speculative Returns}

An exchange-rate speculative strategy is defined as borrowing in the USD asset market and investing the proceeds in foreign-currency denominated assets of similar risk. For this study, USD and other LIBOR interest rates are used. The definition below illustrates an instance of the EUR-USD speculative strategy return between $t$ and $t+1$, which on average should be zero under rational expectations/market efficiency.

$$
\begin{aligned}
& \left\{Q_{U S D} \cdot \frac{1}{S_{t}} \cdot\left(1+i_{E U R}\right) \cdot S_{t+1}-Q_{U S D} \cdot\left(1+i_{U S D}\right)\right\} / Q_{U S D}=r_{t+1} \Rightarrow \frac{S_{t+1}}{S_{t}} \cdot\left(1+i_{E U R}\right)-\left(1+i_{U S D}\right)=r_{t+1} \\
& r_{t+1}=\frac{S_{t+1}+S_{t+1} \cdot i_{E U R}-S_{t}-S_{t} \cdot i_{E U R}+S_{t} \cdot i_{E U R}-S_{t} \cdot i_{U S D}}{S_{t}} \Rightarrow r_{t+1}=\frac{S_{t+1}-S_{t}}{S_{t}} \cdot\left(1+i_{E U R}\right)+\left(i_{E U R}-i_{U S D}\right)
\end{aligned}
$$

This speculative returns definition was first introduced by Bilson (1981). ${ }^{5}$ If markets were efficient then expected speculative returns would be zero, leading to the following testable hypothesis:

$$
E\left[r_{t+1}\right]=0 \Rightarrow E\left[\frac{S_{t+1}-S_{t}}{S_{t}}\right]=-\frac{i_{E U R}-i_{U S D}}{1+i_{E U R}} \equiv-X_{E U R, t}=-\frac{x_{E U R, t}}{1+i_{E U R}}
$$

In literature the efficient market hypothesis is tested with interest rate differentials between domestic and foreign interest rates, which lead to an expected $\beta$-coefficient of +1 and intercept of 0 :

$$
\begin{aligned}
& \log S_{t+1}-\log S_{t}=\alpha+\beta\left(i-i^{*}\right)+\varepsilon_{t+1} \\
& H_{0}: \alpha=0 ; \beta=1 ; E\left[\varepsilon_{t+1} / \varepsilon_{t}\right]=0
\end{aligned}
$$

But in the definition of speculative returns, interest rate differentials are between the foreign and domestic currencies. The expected $\beta$-coefficient is -1 . In describing speculative returns, $i_{E U R}$ illustrates any non-USD interestrate whose subscript will be suppressed below. The efficient market hypothesis is tested as follows:

$$
\begin{gathered}
E\left[\frac{S_{t+1}-S_{t}}{S_{t}}\right]=\tilde{\alpha}+\tilde{\beta} \cdot X_{t}+E\left[\varepsilon_{t+1}\right] \Rightarrow \frac{S_{t+1}-S_{t}}{S_{t}}=\tilde{\alpha}+\tilde{\beta} \cdot X_{t}+\varepsilon_{t+1} \\
H_{0}: \quad \tilde{\alpha}=0 ; \quad \tilde{\beta}=-1 ; \quad E\left[\varepsilon_{t+1} / \varepsilon_{t}\right]=0
\end{gathered}
$$

The estimated equation is obtained after substituting $\left(S_{t+1}-S_{t}\right) / S_{t}$ in speculative returns $r_{t+1}$, and including a trend in interest-rate differentials which partly enhances the effect of current interest rates on returns: ${ }^{6}$

\footnotetext{
${ }^{5}$ John F. O. Bilson, The Speculative Efficiency Hypothesis, Bell Journal of Economics, 1981, 435-451.
} 


$$
\begin{aligned}
& r_{t+1}=\frac{S_{t+1}-S_{t}}{S_{t}} \cdot\left(1+i_{E U R}\right)+\left(i_{E U R}-i_{U S D}\right)=\tilde{\alpha}\left(1+i_{E U R}\right)+(\tilde{\beta}+1) x_{\mathrm{t}}+\varepsilon_{t+1}\left(1+i_{E U R}\right) \\
& r_{t+1}-v_{t}=b_{0}+b_{1} x_{t}+b_{5}\left(x_{t}-\bar{x}_{t}\right)=b_{0}+\left(b_{1}+b_{5}\right) x_{t}-b_{5} x_{t}=b_{0}+\left(b_{1}+b_{5}\right) x_{t}-b_{5}\left\{\delta \cdot \sum_{k=0}^{n-1}(1-\delta)^{k} x_{t-k-1}\right\} \\
& H_{0}: \quad b_{0} \equiv \tilde{a}\left(1+i_{E U R}\right)=0 ; \quad b_{1}+b_{5} \equiv(\tilde{\beta}+1)=0 ; \quad E\left[v_{t+1} / v_{t}\right]=0, \quad v_{t+1} \equiv \varepsilon_{t+1}\left(1+i_{E U R}\right)
\end{aligned}
$$

Speculators also, but less frequently react to a discounted excess yield $X_{t}=x_{t} /\left(1+i_{E U R}\right)$ above a certain level. The spot rate then appreciates based on both linear and nonlinear excess yield effects. The new equation includes a hyperbolic-tangent response of the percent change in spot to discounted interest-rate differentials. Expanding on the Bilson (2007) approach, efficiency for each currency is tested as follows.

$$
\begin{aligned}
& E\left[\frac{\left.S_{t+1}-S_{t}\right]}{S_{t}}\right]=-\frac{x_{t}}{1+i_{E U R}}+\varphi \cdot \frac{\exp \left[2 \cdot\left(\tilde{\alpha}_{N L}+\tilde{\beta}_{N L} \cdot x_{t}\right)\right]-1}{\exp \left[2 \cdot\left(\tilde{\alpha}_{N L}+\tilde{\beta}_{N L} \cdot x_{t}\right)\right]+1}+E\left[\varepsilon_{t+1}\right], \quad \varphi \equiv \frac{\tilde{\varphi}}{1+i_{E U R}} \\
& \frac{S_{t+1}-S_{t}}{S_{t}}=\tilde{\alpha}+\tilde{\beta} \cdot \frac{x_{t}}{1+i_{E U R} t}+\varepsilon_{t+1}=\tilde{\alpha}_{L}+\tilde{\beta}_{L} \cdot \frac{x_{t}}{1+i_{E U R}}+\varphi \cdot \frac{\exp \left[2 \cdot\left(\tilde{\alpha}_{N L}+\tilde{\beta}_{N L} \cdot x_{t}\right)\right]-1}{\exp \left[2 \cdot\left(\tilde{\alpha}_{N L}+\tilde{\beta}_{N L} \cdot x_{t}\right)\right]+1}+\varepsilon_{t+1} \\
& H_{0}^{(I)}: \tilde{\alpha}=\tilde{\alpha}_{L}=0 \text { if } \varphi=0 \text { or } \tilde{\alpha}_{N L}=0 ; \quad H_{0}^{(I I)}: \tilde{\alpha}=\tilde{\alpha}\left(\tilde{\alpha}_{L}, \tilde{\alpha}_{N L}, \varphi, x_{t}^{e}\right)=0 \text { if } \varphi \neq 0 \text { and } \tilde{\alpha}_{N L} \neq 0 ; \\
& \tilde{\beta}=\tilde{\beta}_{L}=-1 \text { if } \varphi=0 \text { or } \tilde{\beta}_{N L}=0 ; \quad \tilde{\beta}=\tilde{\beta}\left(\tilde{\beta}_{L}, \tilde{\beta}_{N L}, \varphi, x_{t}^{e}\right)=-1 \text { if } \varphi \neq 0 \text { and } \tilde{\beta}_{N L} \neq 0 \\
& E\left[\varepsilon_{t+1} / \varepsilon_{t}\right]=0 \quad E\left[\varepsilon_{t+1} / \varepsilon_{t}\right]=0
\end{aligned}
$$

Hypothesis $H_{0}^{(I)}$ implies that all nonlinear effects are zero. Here, estimates of nonlinear coefficients are not zero. Hypothesis $H_{0}^{(I I)}$ is thus relevant, with original linear efficient market coefficients stated as functions of linear/nonlinear coefficients and average interest-rate differentials. The resulting coefficient values of the model proposed are very close to those originally anticipated and subsequently rejected in the efficient market hypothesis literature. A hedging relationship between linear and nonlinear effects transpires across currencies at sample-average values of interest-rate differentials, This linear relationship can be estimated from the distinct coefficients of the model in each currency. As is the case with the original linear model, efficiency is tested using the definition of speculative returns. The model is derived after substituting the above in $r_{t+1}$, denoting $i_{E U R}-i_{U S D}$ as $x_{t}$, and considering the existence of a trend in the variable $x_{t}$ :

\footnotetext{
${ }^{6}$ John F. O. Bilson, A Factor Model for Currency Speculation, Stuart Graduate School of Business, 2007, 14-17.
} 


$$
\begin{aligned}
& r_{t+1}=\frac{S_{t+1}-S_{t}}{S_{t}} \cdot\left(1+i_{E U R}\right)+\left(x_{t}\right)=\tilde{\alpha}_{L}\left(1+i_{E U R}\right)+\left(\tilde{\beta}_{L}+1\right) x_{\mathrm{t}}+\varphi\left(1+i_{E U R}\right) \cdot g\left(x_{t}\right)+\varepsilon_{t+1}\left(1+i_{E U R}\right) \\
& g\left(x_{t}\right)=\frac{\exp \left[2 \cdot\left(\tilde{\alpha}_{N L}+\tilde{\beta}_{N L} \cdot x_{t}\right)\right]-1}{\exp \left[2 \cdot\left(\tilde{\alpha}_{N L}+\tilde{\beta}_{N L} \cdot x_{t}\right)\right]+1} \\
& r_{t+1}=b_{0}+b_{1} \cdot x_{t}+b_{2} \cdot \frac{\exp \left[2 \cdot\left(b_{3}+b_{4} \cdot x_{t}+b_{6} \cdot\left[x_{t}-\bar{x}_{t}\right]\right)\right]-1}{\exp \left[2 \cdot\left(b_{3}+b_{4} \cdot x_{t}+b_{6} \cdot\left[x_{t}-\bar{x}_{t}\right]\right)\right]+1}+b_{5} \cdot\left[x_{t}-\bar{x}_{t}\right]+v_{i . t+1}
\end{aligned}
$$

where $x_{t}=\left(i_{t}^{*}-i_{t}\right) ; i_{t}^{*} \in\left\{i_{A U D, t}, i_{C A D, t}, i_{E U R, t}, i_{J P Y, t}, i_{C H F, t}, i_{G B P, t}, i_{N Z D, t}\right\}$

and $\delta \equiv 1-\lambda ; \bar{x}_{t}=\bar{x}_{t-1}+(1-\lambda) \cdot\left[x_{t-1}-\bar{x}_{t-1}\right]=(1-\lambda) \cdot \sum_{j=0}^{q \leq n} \lambda^{j} \cdot x_{t-j-1}$

Current and lagged values of interest rate differentials affect next-period returns in both the linear and nonlinear terms of the model. These dynamic aspects are determined in similar ways across the two terms. The exponentially weighted moving average coefficient $\delta$ should be between 0 and 2 for stability: ${ }^{7}$

$$
\begin{gathered}
\bar{x}_{t}=\bar{x}_{t-1}+\delta \cdot\left(x_{t-1}-\bar{x}_{t-1}\right) \Rightarrow \bar{x}_{t+1}-(1-\delta) \cdot \bar{x}_{t}=-\delta_{t} \Rightarrow \bar{x}_{t}=\left[\bar{x}_{0}+x_{t}\right] \cdot(1-\delta)^{t}-x_{t} \\
-1 \leq \lambda \leq 1 \Leftrightarrow 0 \leq \delta \leq 2, \quad \lambda=1-\delta
\end{gathered}
$$

In a geometric lag like the one above this stability condition must be fulfilled otherwise the model will diverge from equilibrium values. It is implicitly assumed that lagged variables/trends/expectations are formed uniquely, irrespective of their appearance in the linear or nonlinear part of the returns equation.

\subsection{Testing For Market Efficiency}

This study finds an indication that market efficiency holds at the average point of interest-rate differentials, the average excess yield for each currency. For the Euro that point is (currency subscript is omitted later):

$$
x_{t}^{e}=x_{E U R, t}^{e}=\underset{t}{E}\left[x_{E U R, t}\right]
$$

The estimation of distinct coefficients for each currency illustrates a hedging relation between the linear and nonlinear effects of the intercept, current rates, and lagged rates across currencies. This relation allows for the restatement of the efficiency hypothesis test coefficients in terms of the new linear/nonlinear ones. After the model is estimated, the nonlinear effects of the intercept, current rates and lagged rates are stated in terms of the corresponding linear effect across currencies, as is implicit in the efficiency coefficients,

\footnotetext{
${ }^{7}$ Alpha C. Chiang, Fundamental Methods of Mathematical Economics, McGraw-Hill Co. 1984, 549-575.
} 


$$
\tilde{\alpha}=\tilde{\alpha}\left(\tilde{\alpha}_{L}, \tilde{\alpha}_{N L}, \varphi, x_{t}^{e}\right)=0, \tilde{\beta}=\tilde{\beta}\left(\tilde{\beta}_{L}, \tilde{\beta}_{N L}, \varphi, x_{t}^{e}\right)=-1
$$

\section{Coefficients Related To Risk Premia}

The linear intercept associated with non-interest-rate effects for each currency is $b_{0}$. In studies by Fama and others a large intercept was associated with diversifiable risk premia which were volatile and time-varying. In this study the combined non-market effect (hedged risk premium) is close to zero. Threshold $b_{3}$ imposes a transition between two states as captured by the nonlinear term $g\left(x_{t}\right)$, whose intensity depends on $b_{2}$.

$$
\begin{aligned}
& r_{t+1}^{(0, L)}=b_{0} ; \quad r_{t+1}^{(0, N L)}=b_{2} g(0)=b_{2} \cdot \frac{\exp \left[2 \cdot\left(b_{3}\right)\right]-1}{\exp \left[2 \cdot\left(b_{3}\right)\right]+1} ; x_{t}^{e}=\overline{-}_{t}^{e}=0 \\
& r_{t+1}^{(0)}=r_{t+1}^{(0, L)}+r_{t+1}^{(0, N L)}+v_{t+1}^{(0)}=b_{0}+b_{2} \cdot g_{0}(0)+v_{t+1}^{(0)}=b_{0}+b_{2} \frac{\exp \left(2 b_{3}\right)-1}{\exp \left(2 b_{3}\right)+1}+v_{t+1}^{(0)}+1
\end{aligned}
$$

The regression of the nonlinear against the linear premium across currencies leads to the following relation:

$$
b_{2} \cdot g_{0}(0)=a_{0}+a_{1} b_{0}+u_{t}^{(0)}
$$

Substitution of the above relation in the returns model gives the following estimated coefficient results:

$$
r_{t+1}^{(0)}=b_{0}+a_{0}+a_{1} b_{0}+u_{t}^{(0)}+v_{t+1}^{(0)}=a_{0}+\left(1+a_{1}\right) b_{0}+u_{t}^{(0)}+v_{t+1}^{(0)}
$$

Linear and nonlinear premia partly hedge each other since $a_{0}$ is close to 0 and $a_{l}$ is close to -1 , in Table 2 .

\section{Coefficients Of Current Market Effects}

The slope associated with market effects and the forward premium anomaly for each currency is $b_{1}$. Based on the results of this study previous research that found a positive or near-zero slopes may have attempted to capture two separate effects, the linear and the nonlinear one, in a single estimation coefficient. The nonlinear coefficient associated with transitions across market efficiency for each currency is $b_{4}$. The transition intensity depends on $b_{4}$ and its effect is amplified by the coefficient of the nonlinear term, $b_{2}$.

$$
r_{t+1}^{(1, L)}=b_{1} x_{t} ; r_{t+1}^{(1, N L)}=b_{2} g\left(x_{t}^{e}\right)=b_{2} \cdot \frac{\exp \left[2 \cdot\left(b_{4} \cdot x_{t}^{e}\right)\right]-1}{\exp \left[2 \cdot\left(b_{4} \cdot x_{t}^{e}\right)\right]+1} ; x_{t}^{e}=\underset{t}{E}\left[x_{t}\right] ; \stackrel{-}{x}_{t}^{e}=0
$$




$$
r_{t+1}^{(1)}=r_{t+1}^{(1, L)}+r_{t+1}^{(1, N L)}=b_{1} x_{t}^{e}+b_{2} g_{1}\left(x_{t}^{e}\right)+v_{t+1}^{(1)}=b_{1} x_{t}+b_{2} \frac{\exp \left(2 b_{4} x_{t}^{e}\right)-1}{\exp \left(2 b_{4} x_{t}^{e}\right)+1}+v_{t+1}^{(1)}
$$

The regression of the nonlinear against the linear effects across currencies leads to the following relation:

$b_{2} g_{1}\left(x_{t}^{e}\right)=c_{0}+c_{1} b_{1} x_{t}^{e}+u_{t}^{(1)}$

Substitution of the above relation in the returns model gives the following estimated coefficient results:

$$
r_{t+1}^{(1)}=c_{0}+\left(1+c_{1}\right) b_{1} x_{t}^{e}+u_{t}^{(1)}+v_{t+1}^{(1)}
$$

\section{Coefficients Of Lagged Market Effects}

The slope associated with lagged interest-rate differentials for each currency is $b_{5}$. The nonlinear coefficient related to transitions from lagged differentials for each currency is $b_{6}$. The transition intensity depends on the lagged interest-rate differentials coefficient $b_{6}$ and is augmented by the nonlinear-term coefficient $b_{2}$.

$$
\begin{aligned}
& r_{t+1}^{(5, L)}=b_{5} \cdot\left(x_{t}-\bar{x}_{i}\right)^{\mathrm{e}} ; r_{t+1}^{(5, N L)}=b_{2} \cdot \frac{\exp \left[2 \cdot b_{6} \cdot\left(x_{t}-\bar{x}_{t}\right)^{\mathrm{e}}\right]-1}{\exp \left[2 \cdot b_{6} \cdot\left(x_{t}-\bar{x}_{t}\right)^{\mathrm{e}}\right]+1} ;\left(x_{t}-\bar{x}_{t}\right)^{e}=E\left[x_{t}\right]-E\left[\bar{x}_{t}\right] \\
& r_{t+1}^{(5)}=r_{t+1}^{(5, L)}+r_{t+1}^{(5, N L)}=b_{5}\left(x_{t}-\bar{x}_{t}\right)^{e}+b_{2} \cdot g_{5}\left(x_{t}-\bar{x}_{t}\right)^{e}+v_{t+1}^{(5)}
\end{aligned}
$$

The regression of the nonlinear against the linear effects across currencies leads to the following relation:

$$
b_{2} \cdot g_{5}\left(x_{t}-\bar{x}_{t}\right)^{e}=d_{0}+d_{1} b_{5}\left(x_{t}-\bar{x}_{t}\right)^{e}+u_{t}^{(5)}
$$

Substitution in the returns model gives the following estimated coefficient results:

$$
r_{t+1}^{(5)}=d_{0}+\left(1+d_{1}\right) b_{5}\left(x_{t}-\bar{x}_{t}\right)^{e}+u_{t}^{(5)}+v_{t+1}^{(5)}
$$

Each of the three parts of the model depends on the linear intercept, interest rate and trend, respectively. The sum of these three parts is the total return, and leads to the efficient-market hypothesis coefficients.

$$
\begin{gathered}
a_{0}+c_{0}+d_{0}+\left(1+a_{1}\right) b_{0}=\tilde{\alpha}\left(1+i_{E U R}\right) ; \quad\left[\left(1+c_{1}\right) \hat{b}_{1}+\left(1+d_{1}\right) b_{5}\right]=\tilde{\beta}+1 \\
{\left[v_{t+1}^{0}+v_{t+1}^{1}+v_{t+1}^{5}+u_{t}^{0}+u_{t}^{1}+u_{t}^{5}\right]=\varepsilon_{t+1}\left(1+i_{E U R}\right)}
\end{gathered}
$$




\section{ESTIMATION}

A distinct set of coefficients for each currency interest-rate differential was estimated. The coefficients for each currency are displayed in Table 1 below. The efficient-market-hypothesis coefficients that were based on the maximum likelihood coefficients of this model are shown in Table 2. Exhibits 1, 2 and 3 provide the basic evidence for the existence of a hedging relation between the linear and nonlinear effects of the model.

Table 1: Model Coefficient Estimates

\begin{tabular}{|cccccccc|}
\hline Currency: & AUD & CAD & EUR & JPY & CHF & GBP & NZD \\
$\delta$ & 0.2528 & 0.0050 & 0.0050 & 0.0050 & 0.1293 & 0.0050 & 0.0469 \\
$b_{0}$ & -0.0817 & 0.0925 & -0.0273 & 0.0977 & 0.0149 & 0.0021 & 0.3374 \\
$b_{1}$ & 24.0500 & 24.0830 & 24.0883 & 24.0804 & 24.0610 & 24.0794 & 23.9824 \\
\hline$b_{2}$ & 0.3764 & 0.4188 & 0.3793 & 0.4129 & 0.3501 & 0.4084 & 0.6059 \\
\hline$b_{3}$ & 0.2156 & -0.2211 & 0.0748 & -0.2436 & -0.0209 & -0.0016 & -0.6411 \\
\hline$b_{4}$ & -56.8374 & -56.8270 & -56.8245 & -56.8280 & -56.8360 & -56.8282 & -56.8727 \\
\hline$b_{5}$ & 16.3050 & 16.2584 & 16.2503 & 16.2633 & 16.2947 & 16.2632 & 16.4228 \\
\hline$b_{6}$ & -38.6724 & -38.6905 & -38.6929 & -38.6895 & -38.6782 & -38.6883 & -38.6380 \\
\hline
\end{tabular}

Hedging is evident in the fact that currencies simultaneously exhibit a linear behavior in one direction and a nonlinear behavior in the opposite direction. Exhibits 1,2 and 3 below analyze this inverse relationship as they relate to risk premia, current market values and lagged market effects, respectively. Starting with estimated coefficients $b_{0}$ and $b_{3}$, empirical rejection of the efficient market hypothesis had previously led to the conclusion that risk premia caused large constant terms. Yet here, coefficients $b_{0}$ and $b_{3}$ are inversely related and have opposite signs across all currencies: more (less) positive risk premia have more (less) negative return threshold values. Higher risk premia are associated with the switching between regimes around lower return values. The New Zealand dollar carries the most positive linear intercept $\left(b_{0}=0.3374\right)$ and the most negative nonlinear threshold $\left(b_{3}=-0.6411\right)$. The British pound has the least value of both. In that same low-risk European cluster, the Euro has a negative linear risk premium $\left(b_{0}=-0.0273\right)$ and a positive threshold value $\left(b_{3}=0.0748\right)$ as shown in the top diagram of Exhibit 1 , which is based on the absolute values of $b_{0}$ and $b_{3}$. At average differentials, the combined linear and nonlinear premia for each currency add-up to almost zero. The product $b_{2} g(x=0)$ compensates for intercept $b_{0}$, as depicted by the slope of the fitted line in the bottom diagram of Exhibit 1. If the slope were -1, then the linear premium would be completely compensated by the threshold-induced $b_{2} g(x=0)$. The much smaller excess premium/discount $e p_{0}$ is the difference between the fitted and actual $b_{2} g(x=0)$ values.

Earlier studies on the efficiency hypothesis also found coefficients to excess yields of between 0 and -1 when a value of +1 was expected, thus leading to the concept of the forward premium anomaly (the definition of excess yield is reversed here, therefore the expected efficiency coefficient would be -1). Results support the market efficiency hypothesis, or at least do not point to a forward premium anomaly. Coefficients $b_{1}$ and $b_{4}$ both capture the effect of current interest-rate differentials. Their opposite signs across currencies provide further evidence of hedging, this time between current linear and nonlinear market effects. Currencies with low linear coefficients $b_{1}$ have most negative nonlinear coefficients $b_{4}$. Similarly, estimated coefficients $b_{5}$ and $b_{6}$ have opposite signs across currencies. In addition, the effect of lagged variables is opposite to that of current variables. The New Zealand dollar in particular has a high $b_{0}$ risk premium, a low linear market risk $b_{1}$, and high nonlinear market risk $b_{4}$. This relatively lower-beta asset carries the highest risk of an abrupt adjustment at the lowest threshold value. If this result were generalized, then assets that were desirable from a diversification standpoint could experience the largest adjustments away from average values. The bottom diagrams of Exhibits 2 and 3 show the inverse relationship between the linear and nonlinear sensitivities of speculative returns to interest-rate differentials, and to their trends. Similar to Exhibit 1, the lines almost pass through the origin and have slopes close to negative one. Thus, linear and nonlinear effects to a large extend balance each other out across currencies. Estimates in support of market efficiency largely depend on the hedging relation between linearity and nonlinearity in the effects of intercepts, interest rates and trends. Table 2 shows the resulting efficient-market-hypothesis coefficients. 
Table 2: Efficient Market Hypothesis Coefficients

\begin{tabular}{|c|c|c|c|}
\hline Currency: & $\sim$ & $\tilde{\beta}$ & $\begin{array}{l}\text { Remaining } \\
\text { Trend Effect }\end{array}$ \\
\hline AUD & -0.0018 & -1.1650 & 0.5251 \\
\hline CAD & -0.0044 & -1.1674 & 0.5236 \\
\hline EUR & -0.0026 & -1.1678 & 0.5233 \\
\hline JPY & -0.0046 & -1.1672 & 0.5237 \\
\hline $\mathrm{CHF}$ & -0.0033 & -1.1656 & 0.5247 \\
\hline GBP & -0.0030 & -1.1672 & 0.5237 \\
\hline NZD & -0.0078 & -1.1592 & 0.5289 \\
\hline \multicolumn{2}{|c|}{$a_{0}=$} & $a_{1}=$ & -1.0154 \\
\hline$c_{0}=$ & -0.0046 & $c_{1}$ & -1.0287 \\
\hline$d_{0}=$ & 0.0000 & & -0.9678 \\
\hline
\end{tabular}

The hedging relation between linear and nonlinear effects is based on the whole sample-average interestrate differentials. At sub-sample averages of interest-rate differentials, a different relation may exit that does not support market efficiency. Based on coefficients from the whole sample and interest-rate differential averages from a rolling sample of 60 monthly observations, the three coefficients of Table 2 above were tracked through the sample. Exhibit 4 shows that: (i) hedged risk premia (alphas) for European currencies fluctuate at equal distances between the Australian dollar and the yen, while the New Zealand dollar apparently carries the lowest hedged premium; (ii) sensitivities to current interest-rate differentials (betas) gravitate toward the -1 value of the efficiency hypothesis, and cross that value twice in this sample; (iii) sensitivities to lagged interest-rate differentials gravitate around -1 , with less consistency. Once the coefficient for lagged interest-rate differentials crosses -1 , it does not cross again in this sample.

\section{CONCLUSIONS}

Expected returns from currency speculation should be zero, despite persistent deviations that support the forward premium anomaly. This study suggests that there is equilibrium in speculative returns in line with the original efficiency hypothesis. The basic model of earlier studies was changed to accommodate the existence of a hedging relation between the forward premium effect and the efficient-market adjustment effect, as was apparent from the estimated coefficients. For average interest-rate differentials based on the whole sample, as well as rolling samples, this hedging relation helped obtain coefficients that partly support the original efficiency hypothesis, that is, the intercept was close to zero, and the slope was close to -1 .

\section{AUTHOR INFORMATION}

Apostolos Xanthopoulos started his academic study at the American College of Thessaloniki in Greece and transferred to Kent State University in Ohio for a Bachelor's in Business Administration in Finance. He obtained a Master of Arts in Economics, and a Master of Business Administration at the University of Texas at Arlington. His professional career started at Bank of America where he ascended from operations to counterparty-credit risk and then to global risk control. He worked as supervisor of investment performance and risk analytics at Deutsche Asset Management and also as senior quantitative analyst at the Federal Home Loan Bank of Chicago. He has consulted with KPMG-Bearing Point and independently at various medium-sized investment firms and hedge funds. He is now teaching and pursuing a doctorate degree at the Stuart Graduate School of Business of the Illinois Institute of Technology. His research interests focus around the forward-premium anomaly, kurtosis in utility-maximizing returns, and the nonlinear dynamics of financial markets in general. 
Exhibit 1: Currency Intercepts, Thresholds and Risk Premia

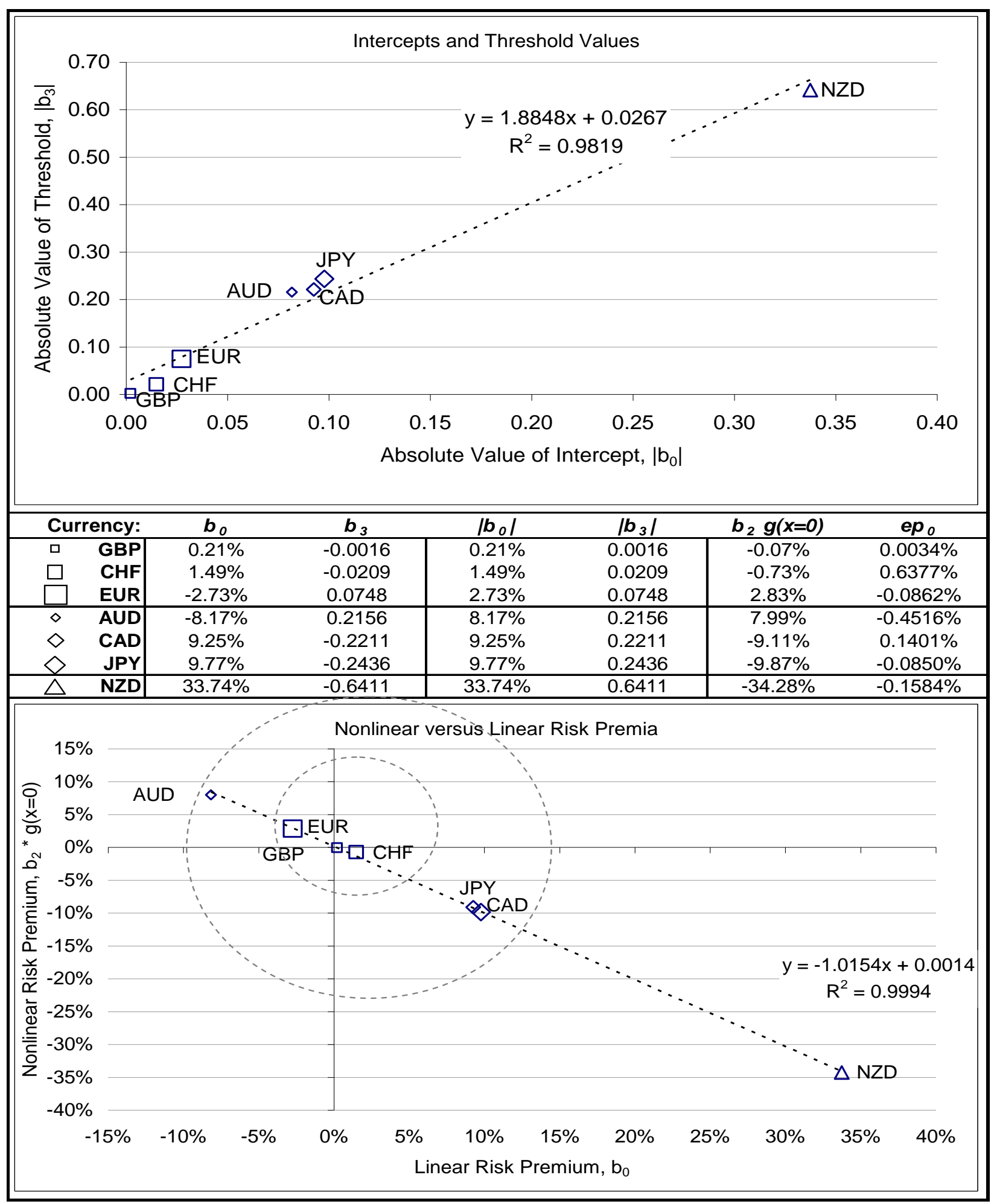


Exhibit 2: Currency Coefficients and Return Sensitivity to Interest Rates

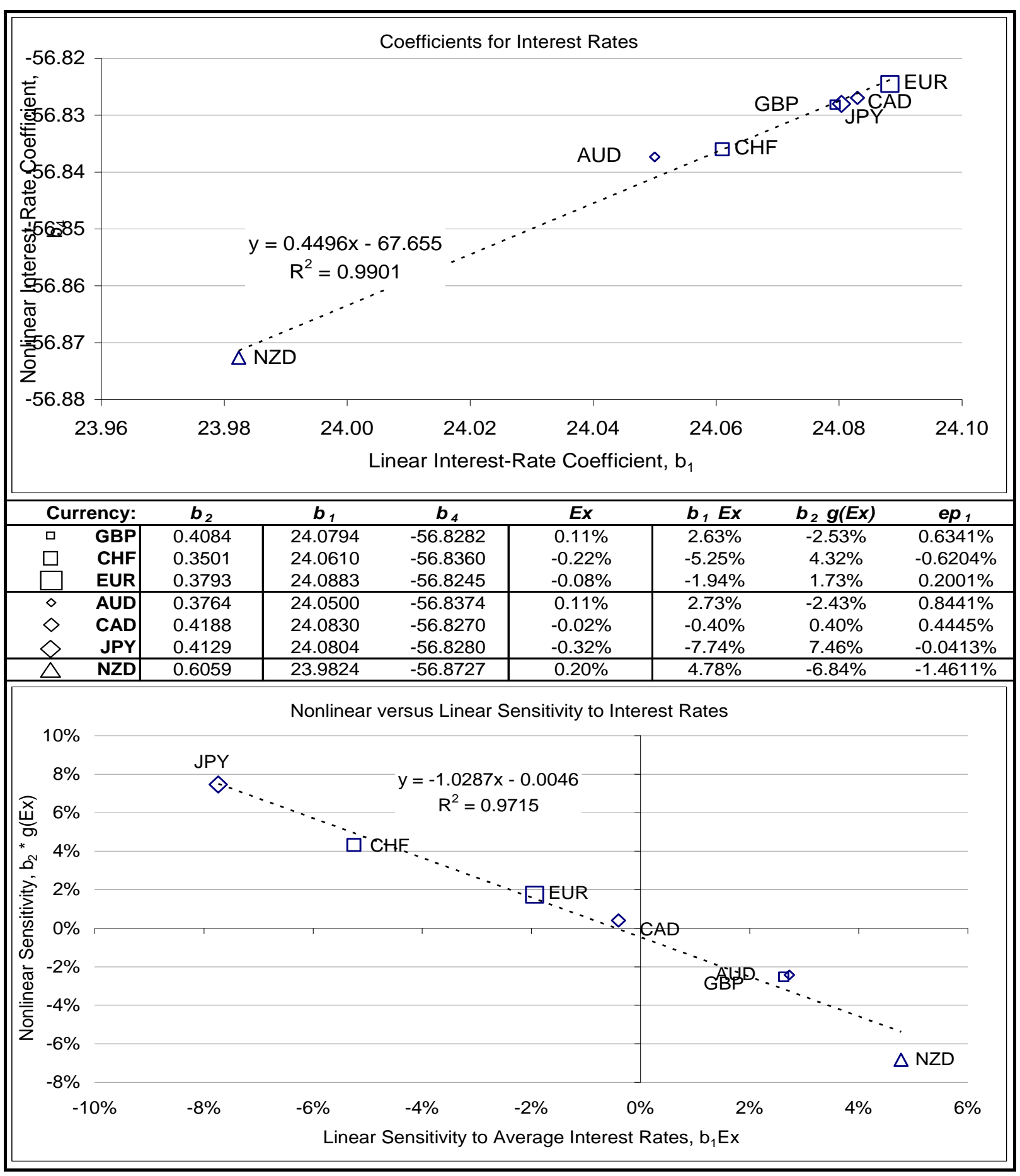


Exhibit 3: Currency Coefficients and Return Sensitivity to Interest-Trends

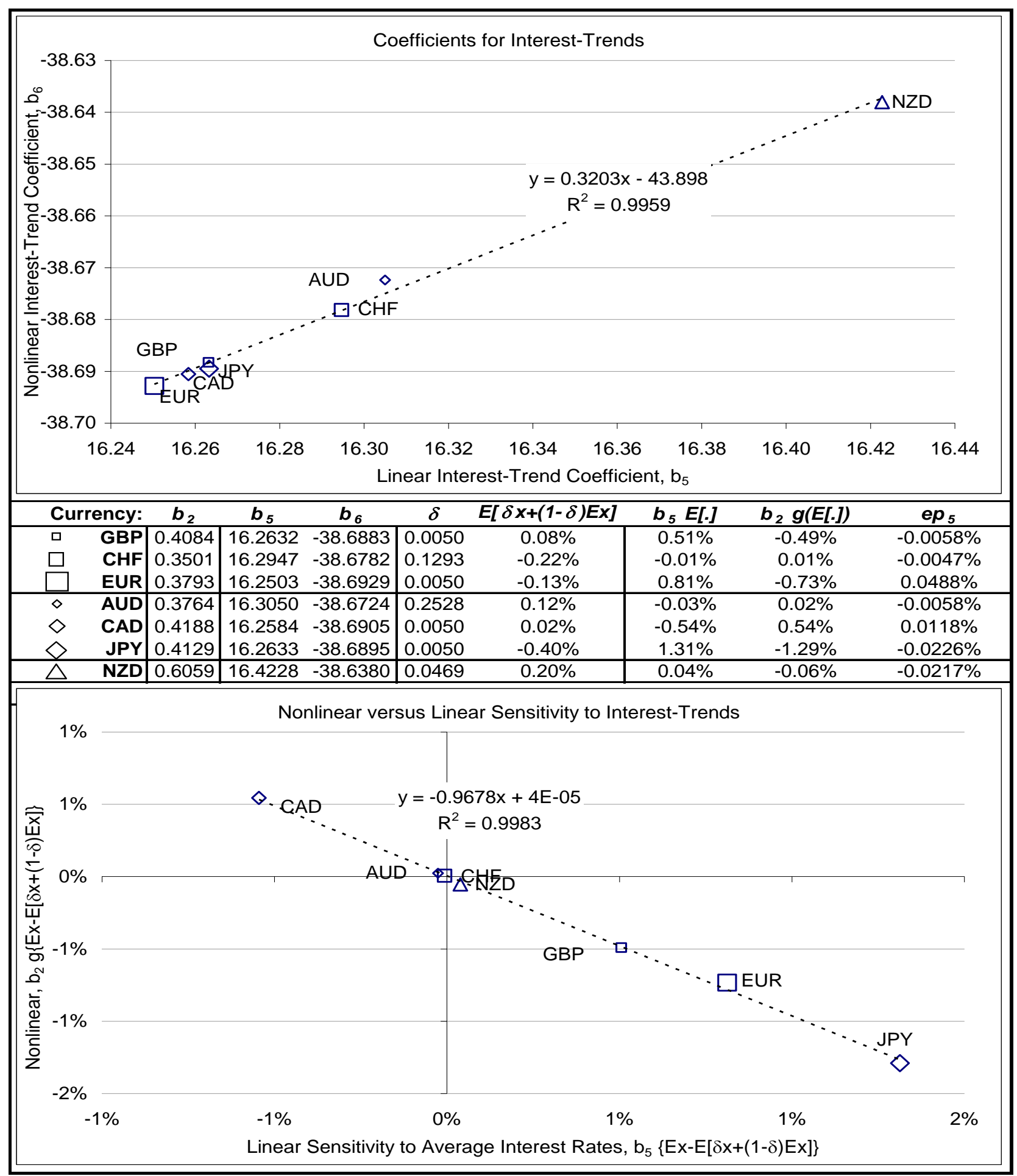


Exhibit 4: Efficient Market Coefficients Based on Rolling Interest Rate Averages
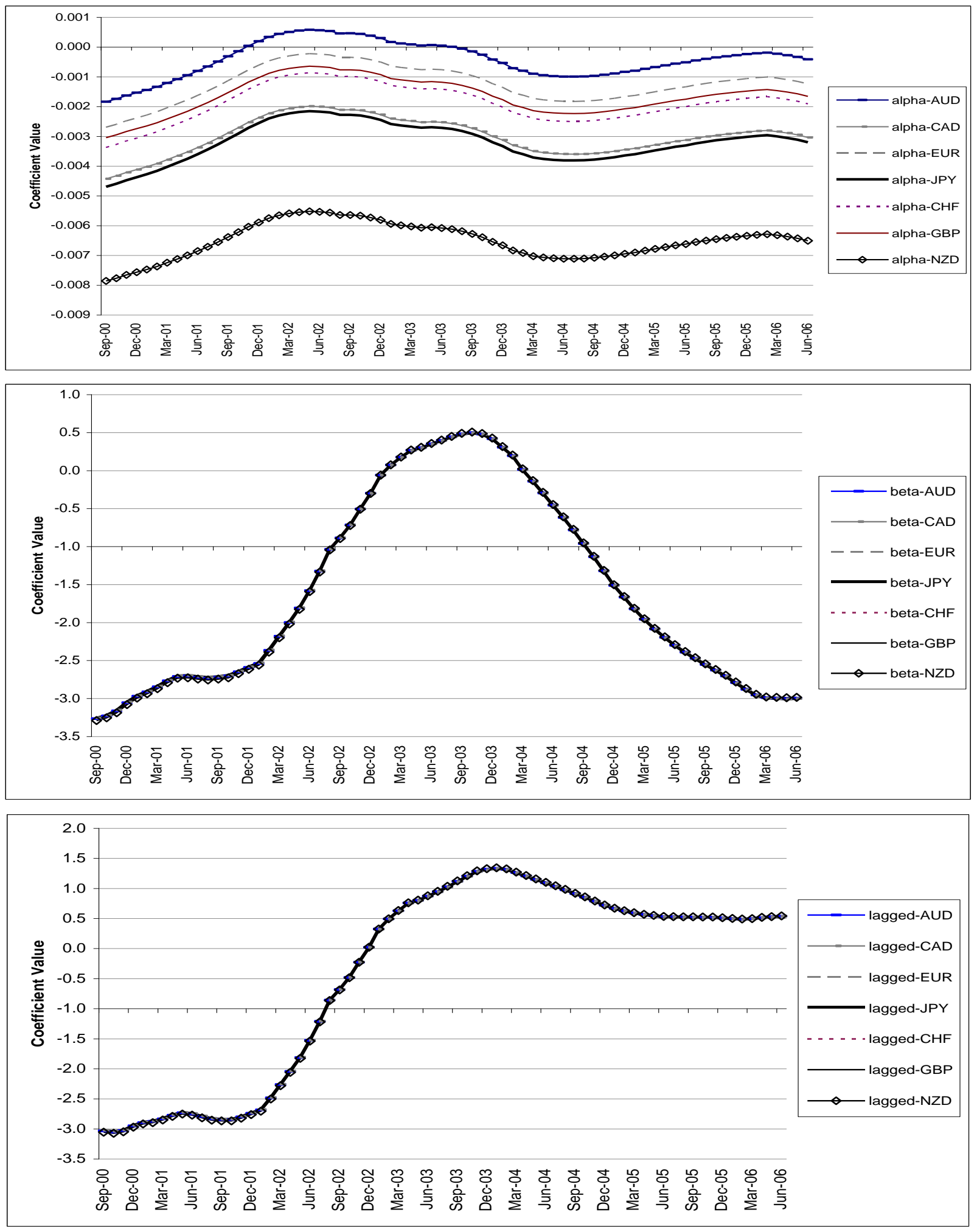


\section{REFERENCES}

1. Backus David K., Silverio Foresi, and Chris I. Telmer. Interpreting the Forward Premium Anomaly. The Canadian Journal of Economics, 28 (Nov. 1995), 108-119.

2. Bilson, John F. O. The "Speculative Efficiency" Hypothesis. The Journal of Business, 54 (Jul. 1981), 435451.

3. Bilson, John F. O. The Non-Linear Dynamics of Exchange Rates. Stuart Graduate School of Business, (1999).

4. Bilson, John F. O. A Factor Model for Currency Speculation. Stuart Graduate School of Business, (2007).

5. Chiang, Alpha C. Fundamental Methods of Mathematical Economics. New York: McGraw-Hill Co., 1984.

6. Chiang, Thomas C. The Forward Rate as a Predictor of the Future Spot Rate-A Stochastic Coefficient Approach. Journal of Money, Credit and Banking, 20 (May 1988), 212-232.

7. Fama, Eugene F. Forward and Spot Exchange Rates. Journal of Monetary Economics, 14 (1984), 319-338.

8. Frankel, Jeffrey A. Tests of Rational Expectations in the Forward Exchange Market. Southern Economic Journal, 46 (Apr. 1980), 1083-1101.

9. Franses, Philip Hans, and Dick van Dijk. Nonlinear Time Series Models in Empirical Finance. Cambridge: Cambridge University Press, 2000.

10. Froot, Kenneth A., and Richard H. Thaler. Anomalies: Foreign Exchange. The Journal of Economic Perspectives, 4 (Summer 1990), 179-192.

11. Greene, William. Econometric Analysis. Upper Saddle River: Prentice Hall, 2000.

12. Kmenta, Ian. Elements of Econometrics. New York: MacMillan, 1971.

13. Markowitz, Harry. Portfolio Selection. The Journal of Finance, 7 (Mar. 1952), 77-91.

14. Priddy, Kevin L., and Paul E. Keller. Artificial Neural Networks: An Introduction. Bellingham: SPIE-The International Society for Optical Engineering, 2005.

15. Refenes, Apostolos-Paul, ed. Neural Networks in the Capital Markets. Chichester: John Wiley \& Sons, Inc., 1995.

16. Sharpe, William. A Simplified Model for Portfolio Analysis. Management Science, 9 (Jan. 1963), 277-293.

17. Sharpe, William. Capital Asset Prices: A Theory of Market Equilibrium Under Conditions of Risk. The Journal of Finance, 19 (Sep. 1964), 425-442.

18. Taylor, Mark P. The Economics of Exchange Rates. Journal of Economic Literature, 33 (Mar. 1995), 1347.

19. Trippi, Robert R., and Efraim Turban. Neural Networks in Finance and Investing. Chicago: Probus Publishing Company, 1993. 
NOTES 